\title{
Research on the Exploitation of Tasty Food Tourism - - Taking Chengdu Cuisine as an Example
}

\author{
Ping Fang \\ School of Management, Shanghai University, Shanghai, China \\ Email: fp13813137729@126.com
}

\begin{abstract}
Tourists are inseparable from the element of food in the process of tourism. Chengdu is known as the "Culinary Capital". Chengdu's rich and varied cuisine is inextricably linked to its natural geographical conditions, historical and cultural background. Based on the actual situation and basic characteristics of Chengdu, this paper proposes the idea of developing Chengdu food tourism based on the existing resource conditions, and develops ancient town food tourism, religious food tourism and gourmet culture tourism of the Three Kingdoms.
\end{abstract}

Keywords: Food tourism, resource development, Chengdu cuisine

\section{Introduction}

In the tourism, travel, housing, food, purchase, entertainment industry chain, "food" can bring a direct taste experience to tourists, and with the modern tourism from sightseeing to leisure and holiday, food can be more Increasing the attractiveness of destinations and the likelihood of visitors visiting destinations has become an important pull factor in destination marketing and has largely affected visitor satisfaction. Nowadays, gourmet tourism is rapidly becoming a popular and interesting form of tourism. Tourism gourmet food can not only provide tourists with the food experience process of destination, but also have the value of social interaction and cultural experience. ${ }^{[1]}$ The catering culture of a destination is closely related to its regional culture. The so-called "one side nourishes one side by water and nourishes one side by people". It will become a new way to promote tourist destinations by endowing the cultural connotation of the destination with gourmet food and expressing the brand personality of the destination with gourmet food.

\section{Overview of Food Tourism Research}

\subsection{The Meaning of Food Tourism}

Food is an important part of the destination tourism resources. Tourists want to experience different local food cultures during the tour, including trying novel foods and participating in food festivals. Even some tourists go to a destination because of the attraction of food, that is, "food tourism".

Food tourism is a kind of folk tourism. It focuses on "participation", combining food culture with tourism activities, and exploring local food culture while tasting food, including appreciation of food art, cooking methods, food experience, food etiquette, utensils, appliances, etc. Tourists are not only pursuing the experience of food culture, but also more eager to participate in this process. Therefore, this is a higher level of tourism activities. ${ }^{[2]}$

\subsection{Characteristics of Food Tourism}

\subsubsection{Regionality}

Because of the differences in climate, products and customs, Chinese food has formed different cuisines. The eight most representative cuisines are Sichuan, Shandong, Huaihe, Guangdong, Fujian, Hunan and Zhejiang. Each cuisine has its own unique cooking style and long history. It is also inseparable from its unused geographical location, natural climate, customs and folk customs. The regional characteristics of 
gourmet tourism resources stimulate the tourism motivation of gourmet tourists, resulting in the spatial mobility of gourmet tourists.

\subsubsection{Culture}

Food tourism and culture are inseparable, and it is a combination of food and culture. Different regions and nationalities have different food cultures. Tourists living in different regions also have different understanding of food culture. Therefore, tourists will be influenced by cultural factors, thus affecting the value judgment of food tourists on tourism resources.

\subsubsection{Artistry}

The process of gourmet tourism emphasizes that tourism activities should be artistic. Tourists who pay attention to the "color, aroma, taste, type and apparatus" of dishes attach importance to the environment, atmosphere and mood of enjoying gourmet dishes enjoy the dual pleasure of body and mind in the process of experiencing gourmet dishes.

\subsubsection{Participation}

The participation of gourmet tourism is much stronger than other types of tourism. The main way of gourmet tourism is to taste gourmet food, which can be directly perceived by the senses. This kind of participation directly affects the length of travel time, and the quality of gourmet itself will affect the level of tourism satisfaction. Moreover, gourmet tourism is not limited to gourmet food tasting, but also arouses tourists' interest by watching tea art performances and participating in gourmet food production.

\section{Analysis of Food Resources in Chengdu}

\subsection{Background of Chengdu Food Resources Formation}

\subsubsection{Natural factors}

Chengdu is located in the central part of Sichuan Province and the western part of Sichuan Basin. It belongs to subtropical monsoon climate. It is suitable for the growth of crops. Dujiangyan Water Conservancy Project can avoid flood disasters. The favorable conditions make Chengdu rich in food raw materials and provide good material conditions for Chengdu food culture.

\subsubsection{Humanistic factors}

Chinese traditional philosophy holds that "the unity of man and nature" has formed a triple culture of people-centered man, earth and heaven. This idea directly affects the Chinese dietary culture. It holds that diet should not only meet people's physiological and psychological needs, but also change with the changes of times, economy, environment and other factors, which will inevitably lead to changes in people's consumption concept and dietary needs. Qingcheng Mountain in Chengdu is one of the birthplaces of Taoism in China. The Taoist doctrine of "immortality" is also human-centered in nature. Chengdu is deeply influenced by traditional Chinese philosophy. The formation process of its dietary culture is also people-centered and strives to meet people's dietary needs. ${ }^{[3]}$

\subsubsection{Economic factors}

Chengdu has been the political, cultural and economic center of Sichuan since its founding in 331 BC. Sichuan embroidery is one of the four famous embroidery in China. China is the first country to drink tea. Xinjin in Chengdu is the first area to trade tea. Chengdu's catering culture has developed with Chengdu's industry and commerce.

\subsubsection{Immigration factors}

Chengdu is an immigrant city. There are four times immigrants in history. Immigrants bring immigrant culture and customs. This constitutes the multi-level nature of Chengdu culture and makes Chengdu culture more inclusive. While maintaining its original culture, Chengdu's catering culture is also 
compatible with the characteristics of local catering culture, thus gradually developing into a broad and sophisticated one. Deep and distinctive local catering culture. ${ }^{[4]}$

\subsection{Elements of Chengdu Food Resources}

\subsubsection{Food resources}

Sichuan cuisine originated in Shu during the Spring and Autumn Period and Warring States Period. It first appeared in Qin and Han Dynasties. Classical Sichuan cuisine was shaped in Han and Jin Dynasties, featuring "spicy and delicious". Classical Sichuan cuisine developed further in Tang and Song Dynasties. Classical Sichuan cuisine came out of Sichuan, and "Sichuan cuisine restaurant" spread all over Kaifeng and Linan, the capital city. With its unique flavor, Sichuan cuisine won the favor of many diners. As an independent cuisine, Sichuan cuisine formed in the Song Dynasty. During the Ming and Qing Dynasties, Sichuan cuisine developed further. Until the Republic of China, modern Sichuan cuisine finally formed the characteristics of "one hundred dishes, one hundred flavors", "fresh and mellow, peppery and spicy", and developed into the first cuisine of Chinese cuisine. ${ }^{[5]}$

\subsubsection{Historical events}

Chengdu's food resources are not only diverse in taste, but also have a long history. Almost every snack has its own historical allusions, citing the historical allusions of several classic Sichuan dishes.

\begin{tabular}{ll}
\hline Dish name & Literary quotation \\
\hline Hot Pot & Originated in Chongqing, the boatman and the tracker added a variety of dishes to the \\
& earthen jar in order to get rid of the cold in the body, and added pepper and sea pepper, \\
& which became a hot pot for a long time. \\
Long Chao Shou & In the 1940s, it was created by the owner of Chengdu's most famous "Thick Flower Tea \\
& Club" at that time, and used "Thick" as a means of "Dragon and Phoenix" for "Dragon and \\
& Phoenix Chengxiang". \\
Translucent Beef & It has a very long history, more than 1,000 years ago. Legend has it that Yuan Qi, a poet of \\
Slices & Tang Dynasty, served as Sima in Tongzhou (now Dazhou) of Sichuan Province, drank in a \\
& rural hotel in Luohuaxi. He found that the beef sold in the shop was as thin as paper, and \\
& held it before the lamp. The lamp shadow could be seen faintly. The details were spicy and \\
& delicious, and the aftertaste was long, so he was named "Lantern Shadow Beef". \\
& Among the various Dandan noodles, the most famous one is that offered byChen Baobao, \\
& which was established in1841 by a peddler named Chen Baobao in Zigong. It was originally \\
Dandan noodles & named for peddling along the street with a burden. \\
& Founded in the first year of Tongzhi in the Qing Dynasty (1862), it was founded in the \\
& "Chen Xingsheng Dinner Shop" beside Wanfu Bridge outside Chengdu. The small \\
& restaurant is managed by the landlady. The landlady's face is slightly numb. Chen Ma-po is \\
known as Chen Ma-po. Chen has a set of unique cooking skills for cooking tofu. The tofu is & full of color and flavor, and the food-seekers are eager to eat it. When a good person sees a \\
pockmark on the face of his wife, he jokingly calls it "Chen Mapo Tofu".
\end{tabular}

\subsubsection{Food enterprises}

Chengdu's catering enterprises mainly include Sichuan restaurants, hot pot shops, snack shops and teahouses.

Some people used to describe Chengdu's delicacies as "if every meal was changed into a restaurant, even in Chengdu for three years, it would not be able to eat all the delicacies". Among them, the representative Sichuan cuisine restaurants include Ronghe, Paguo cloth, vegetable root incense, etc. The chafing dish restaurants include Tan Yutou, Saner, Huangcheng Mama, etc. The snack shops rely on Tangyuan, dragon handwriting, Chen Mapo tofu and so on. Chengdu is famous for its delicacies.6 It has Sichuan cuisine and tea houses. Therefore, it has the saying that "the number of tea houses in the world is China, the number of tea houses in China is Sichuan, and the number of tea houses in Sichuan is Chengdu". Chengdu's tea culture has a long history, especially the teahouse culture. It can be said that Chengdu people's time is 
soaked in tea, tens of thousands of tons of tea are drunk every year, and more than 1.2 million teahouses are brewed every day. Chengdu is a famous cultural city with a long history. The precipitation of history endows Chengdu people with profound tea culture. Tea plays an important role in Chengdu people's life. Teahouses can be seen everywhere in Chengdu. The famous teahouses include Shunxin Old Teahouse, Yuelai Teahouse, Shengtaosha Teahouse, etc.

\subsection{Characteristics of Chengdu Food Tourism Resources}

\subsubsection{Chengdu cuisine has unique taste}

Chengdu snacks are famous not only for their variety, but also for their unique taste. Most of Chengdu's catering materials are ordinary, but its ingredients and workmanship are very exquisite. Its main five tastes are: red bean oil, white bean oil, straw fruit, anise, garlic puree, onion, salt, pepper, hot oil pepper, soybean powder, ginger juice, sesame oil, mustard, orange peel, sweet wine, etc. The exotic five tastes are also unambiguous, such as red bean oil of Pengxian, Shiyu, snowflake salt of Ziliujing, Baoning vinegar and Peizi County bean petals, all contributing greatly to Chengdu's diet. For example, it is difficult to produce the traditional authentic flavor of cooked back-pot meat and fish-flavored pork shreds without the use of Danxian Bean Flap and pickled pepper in Sichuan. ${ }^{[7]}$

Chengdu snacks are unparalleled in many other places. There are more than ten kinds of snacks, such as sweet, salty, strange, home-made, spicy, salty, sweet and sour, pepper and hemp, red oil, garlic paste, and each kind of taste has its own usage methods and changes according to different dishes or season.

\subsubsection{Chengdu food price is civilian}

The popularity is a typical feature of Chengdu catering culture. Chengdu snacks are of good quality and low price, 3 yuan for a pot top, 5 yuan for a portion of dough, hot and sour powder, 10 yuan for a portion of steamed beef powder, a dozen yuan for all kinds of snacks can be tasted. It is the words "cheap" and "popular" that make Chengdu snacks very popular. They can be eaten as long as they want to eat. They are really integrated into Chengdu people's lives. The price of tourist products will affect tourists' choice of tourist destination. Chengdu's food with high cost performance is one of the most important factors for tourists to choose the place.

\section{Advantages of Chengdu Food Tourism Development}

\subsection{Superior Geographical Position}

Chengdu is the capital city of Sichuan Province, a famous historical and cultural city, the home of the national treasure panda, and the main distribution and transit center of tourism in the western region. Chengdu has a permanent population of 14.0476 million, ranked fourth in the country, with a large population flow. There are a large number of natural and cultural scenic spots around Chengdu and a large number of tourists.

\subsection{Food Tourism Resources Have a Long History}

Sichuan cuisine has a long history, which began in Qin and Han Dynasties. After thousands of years, it belongs to one of the eight major cuisines. There are more than 3000 varieties of famous cuisine and 300 varieties of famous cuisine. Basically, every dish has allusions. Famous cuisine and celebrities complement each other and increase the cultural heritage of gourmet tourism.

\subsection{Government Departments Attach Importance to the Development of Gourmet}

\section{Tourism}

Sichuan cuisine industry is an advantageous industry in Chengdu. Sichuan cuisine stands out among the eight major cuisine families and takes the first place in the market share. The development of Sichuan cuisine can promote the development of Sichuan tea, Sichuan wine, tourism and other industries. Sichuan 
Provincial Party Committee and provincial government put forward the idea of developing Sichuan cuisine industrialization, which is the first in the country. In 2004, Sichuan Merchants Bureau held the first Sichuan Cuisine Expo and Chengdu Municipal Government held the first China International Food Tourism Festival.

\subsection{Food Tourism Resources Are Rich in Variety and Can Be Combined}

Chengdu is rich in tourism resources. The combination of gourmet tourism resources and various tourism resources will enrich the diversity of tourism resources and enhance tourism attraction, such as the culture of the Three Kingdoms and the gourmet food of the Three Kingdoms, Buddhist resources and Buddhist cuisine, Taoist resources and Taoist cuisine, tea house culture and name, farm delicacies in rural tourism, and so on.

\subsection{Strong Tourism Development}

Sichuan Province is rich in tourism resources and attracts many tourists. In 2017, Chengdu received 210 million tourists and achieved total tourism revenue of 303.342 billion yuan, of which 301.333 million tourists were received, an increase of $10.66 \%$ over the previous year. By the end of the 13th Five-Year Plan, the total number of tourists in Chengdu may exceed 230 million, and the total tourism revenue will exceed 520 billion yuan. Strong tourist groups provide a source of tourists for the development of food tourism in Chengdu.

\section{$5 \quad$ Development Conception of Chengdu Food Tourism Resources}

\subsection{Gourmet Tourism in Ancient Town}

Chengdu is a famous cultural city with a long history. There are many historic towns around it. We can use the resources of the ancient towns to develop the gourmet tourism of the ancient towns. We can provide the gourmet service of the ancient towns by relying on the local customs and cultural relics of the ancient towns and taking the gourmet food of the ancient towns as the theme. Luodai Ancient Town, built in the Shuhan Period of the Three Kingdoms, has a relatively complete Hakka culture. There are many exquisite ancient architectural communities in the town, featuring Hakka delicacies such as brewed tofu, Aiye Miguo, fried horn, tasty cellar rice, etc. Pingle Ancient Town in Qionglai City has a history of more than 2,000 years. It is the first post station on the Silk Road in history. The ancient streets in this town are well preserved, and the folk houses with the characteristics of Western Sichuan are also a major feature. The special delicacies include milk soup noodles and bowled chicken. The ancient town of Jiezi in Chongzhou is a well-known orchid town in China. Its historic sites and streets are well preserved. Its special delicacies include street sesame cakes, chicken bean flowers, dried roasted rock carp, aged eggs and so on.

\subsection{Religious Food Tourism}

Chengdu is rich in religious resources, with Buddhism and Taoism having the greatest impact. Chengdu is one of the birthplaces of Taoism. With Taoist culture as the clue and Taoist health food as the theme, Chengdu Taoist Food Tourism Festival is launched, and Taoist feasts and other meals with Taoist characteristics are vigorously developed and promoted. ${ }^{[8]}$

Chengdu also has abundant Buddhist resources, such as Manjushu Temple, Zhaojue Temple, Daci Temple, Shijing Temple and Baoguang Temple. Among them, Zhaojue Temple is known as the "First Zen Forest in West Sichuan" and has an important position in the history of Buddhism in China. Baoguang Temple is one of the "Four Buddhist Jungles" in the south, and it is the oldest, largest and richest temple with cultural relics in Chengdu. For the Museum of Cultural Relics. It is possible to develop Buddhist food tourism starting from Chengdu Buddhist resources and extending to Leshan and Emei Mountains. Mount Emei is one of the four major Buddhist mountains in China, and it is a world natural and cultural heritage. Leshan has the largest stone Buddha in the world, and it is also a world natural and cultural heritage. It has great influence on Buddhism in China and even in the world, and attracts many tourists to worship. 
We should make full use of this resource, take Buddhist culture as the clue, and take Buddhist food as the theme to develop Chengdu Buddhist food tourism.

\subsection{Gourmet Tourism in the Three Kingdoms}

Chengdu has abundant cultural tourism resources, high resource grade and rich cultural connotation. The main relics of the three countries are Wuhou Temple, Wanli Bridge, Jiulidi, Mimou Bamatu Relics, Dayi Zilong Temple, Zhaoyun Tomb, etc. Chengdu's three-nation cultural tourism resources, with high taste and distinct cultural connotation, are widely recognized as the cultural center of the three countries at home and abroad. Most of the scenic spots are distributed along the main traffic lines, which has a strong practical development value, and is easy to form tourist routes and organize tourists. However, the construction and development of some sites have not undergone rigorous research and demonstration. They have been launched rashly, lack of protection consciousness, insufficient cultural connotation, overweight commercial color, and some even cause "constructive breakdown". According to the characteristics of the cultural tourism resources of the Three Kingdoms in Chengdu, we should develop the cuisine tourism of the three kingdoms, fully tap the cultural connotation of the tourism resources of the three kingdoms, and display the unique characteristics of the cuisine tourism of Chengdu. We can develop the cuisine tourism of the Three Kingdoms by taking the Wuhou Temple as the leading place, combining the cultural relics of the other three kingdoms and When exploiting the cuisine tourism resources of the Three Kingdoms, we should take the culture of the Three Kingdoms as the clue and combine the stories and allusions of the famous figures of the Three Kingdoms to design a set of "Three Kingdoms Banquet". The dishes can be of various grades and collocations.

\section{References}

1. Tang Yong, Liu Yan, Liu Nan. Research on Integration and Development of Tourism Resources of Jinli Folklore Culture in Chengdu [J]. Journal of Chengdu University of Science (Social Science Edition).2008,(1):6-17.

2. Deng Wen, Liu Xiaoying. The Development Characteristics of Rural Tourism in Chengdu: Leisure Holiday and Cultural Tourism [J]. Resource Development and Market. 2006,(6): 1-9.

3. Liu Deqian. Development Orientation and Image Orientation of Chengdu Tourism [J]. Journal of the Party School of the Chengdu Municipal Party Committee of the Communist Party of China. 2006, (1): 35-46.

4. Zhu Taoxing, Lu Lin, Jiang Xiulan. A Preliminary Study on the Development of Food Tourism Products in Wuhu City [J]. Resource Development and Market,2005, (2):28-30.

5. Li Xiangyun, Lv Xingyang. Study on Food Elements in Tourism Destination Image: A Case Study of Chengdu [J]. Research on the Tasty Food,2017,(7):11-16.

6. Feng Min. The Impact of Immigrants on Sichuan Food Culture: A Historical Perspective [J].Study on Food Culture, 2006,(11):105-106.

7. Zhang Tao.Study on the Perception Quality and Promotion Strategy of Food Festival [J]. Tourism Tribune,2010,(12):37-40.

8. Cheng Li, Lu Youhai. The Brand Individuality and Impact of Gourmet Tourism Destination in the Perspective of Confucian Culture [J]. Tourism Tribune, 2018, (10):25-41. 